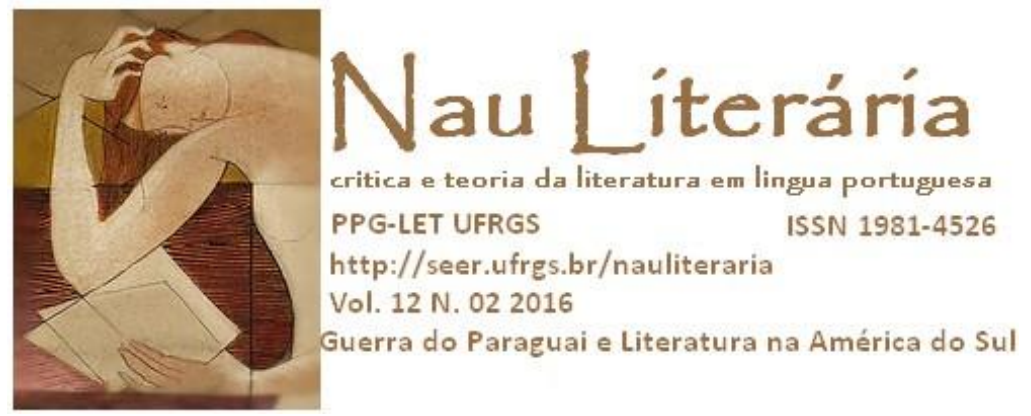

\title{
Guerra em deriva: Poéticas de fronteira
}

\section{Rita Lenira de Freitas Bittencourt}

UFRGS

Resumo: Do enfrentamento sangrento que marcou as divisões territoriais e o espaço do imaginário das três nações envolvidas — Argentina, Uruguai e Paraguai — somadas ao Brasil, ainda Império —, a Guerra do Paraguai, Guerra da Tríplice Aliança, ou Grande Guerra do Brasil, reverbera, no presente, suas poéticas: são derivas multilíngues e oscilantes, que carregam nos usos da língua os rastros e as formas dos contatos e conflitos. Especialmente em espaços fronteiriços, recompõem-se e reinventam-se as diç̧ões em convívio, nas quais o espanhol, o guarani e o português se reconhecem e se estranham.

Paravras-chave: Poesia; guerra; fronteiras; portunhol; portuñol.

Abstract: From the bloody confrontation that marked territorial divisions and imaginary space of the three nations involved — Argentina, Uruguay and Paraguay — added to Brazil, still an empire —, the War of Paraguay, War of the Triple Alliance, or Great War of Brazil, reverberates, in the present, its poetics: they are multilingual and oscillating drifts, which carry in the uses of language traces and forms of contacts and conflicts. Especially in frontier spaces, the dictions in contact are reconstituted and reinvented, in which Spanish, Guarani and Portuguese recognize and mix themselves.

Keywords: poetry, war; borders; portunhol; portuñol.

Contam os veteranos do Paraguai que rasgavam no dente o cartucho misturavam pólvora com aguardente, passavam a mistura no bucho e depois iam brigar...

...

Ascenso Ferreira. Canna caiana. 1939.

\section{Guerra e tempo presente ${ }^{1}$}

${ }^{1}$ Esta é uma parte, vertida ao português, do artigo Veredas poético/políticas de la experimentación: literatura del presente y lenguas de frontera, apresentado em Bogotá, no "Primer Encuentro Internacional 
A Grande Guerra do Brasil, da Argentina e do Uruguai contra o Paraguai, no final do século XIX (1864-1870), figura como marca sangrenta no passado das nações do sul e também desenha o futuro político e cultural dessa região ${ }^{2}$. De certo modo, desde as primeiras relações de enfrentamento, a guerra impõe, também, a necessidade de convivência, e, passado o tempo das invasões territoriais, das matanças e dos abusos, o que resta, para além dos mapas dos estados nacionais, são as memórias incompletas do trauma, as imagens esparsas da destruição e os fiapos narrativos e poéticos de uma coletividade temporária, que se uniu em torno da luta e se desfez depois dela.

Como acontecimento, no sentido discursivo, a guerra é pensada, hoje, em campo multidisciplinar, e, por colocar imagens e palavras em movimentos de colisão e de diálogo, tem importante lugar no plano da literatura e das artes.

No livro Guerra e Poesia. Dispositivos bélico-poéticos do modernismo, de 2014, minha preocupação teórica foi a de montar, de forma intertextual, um tratado da guerra modernista, desde a literatura e a pintura, e em âmbito latino-americano. As imagens da guerra contra o Paraguai participaram, nesse trabalho, como temática e forma simbólica das lutas que mobilizaram as vanguardas artísticas. Em deriva, investigo os usos de corpos e vozes populares pela cultura letrada, as subversões linguísticas e espaciais e as definições de estratégias e os dispositivos bélico-poéticos que sustentaram os conflitos políticos futuros, em direções distintas: de um lado, configurando uma modernidade em declínio, identitária, que defende uma dicção que se acomoda e participa da fundação dos Estados Nacionais; e de outro, uma modernidade em ascensão, "sem terra", que postula uma espacialidade transnacional e translinguística, de ultrapassagem das fronteiras. No jogo entre esses movimentos, simultâneos e não excludentes, funda-se um presente paradoxal e múltiplo.

O tempo presente é um problema teórico, seja porque o estamos vivendo, e a proximidade nos ofusca, toldando as leituras de contexto, seja porque é muito difícil falar daquilo que nos inclui, que nos toca e nos mantém em suspensos no imediato da linguagem. Segundo a teórica argentina Josefina Ludmer, em "Temporalidades del presente" (2002), o presente é tanto o modo como o lemos, em meio à multiplicidade de

de Literatura Comparada — Después de Babel: La Literatura como discurso políglota", na Universidad Nacional de Colombia, em 2013. A versão em castelhano ainda aguarda publicação.

${ }^{2}$ Esta hipótese é desenvolvida no livro Guerra e poesia: dispositivos bélico-poéticos do modernismo (2014), que convoca uma cena sul-americana heterogênea e modernista, na qual imagens visuais, poemas e outros textos são entendidos com dispositivos de guerra com papel político na formação das nações, em tempo futuro, quando também irão apresentar um tom desviante, apontando as pulsões utópicas da língua e do verso. 
informações e de registros cotidianos, quanto a própria definição de seus caminhos críticos, necessariamente traçados e submetidos às dimensões do provisório e do precário. Na obra Aquí América latina. Una especulación (2010), Ludmer volta a discutir essas questões ao falar de temporalidades, no plural, e, sobretudo, identifica o "tempo zero", que identifica a experiência histórica do tempo digital e atravessa, rápida e intermitentemente, também, os espaços:

En los últimos años vivimos con Internet una nueva experiencia histórica global: el tiempo cero, la travesía del espacio en lo tiempo, lo que se llama tiempo real. El resultado de la aniquilación temporal es la simultaneidad global, clave para los mercados financieros que cambió la experiencia de la vida y la naturaleza del trabajo convirtiéndolo en trabajo inmaterial. El entre tiempo cero reorganiza el mundo y la sociedad y produce todo tipo de fusiones y divisiones. Borra la diferencia entre "lejos" y "aquí", y libera el tiempo de la subordinación a la idea de espacio. Por un lado fusiona los opuestos y hace porosa las fronteras entre tiempo privado y público, entre presente y futuro, y también entre ficción y realidad. Y por otro lado divide la sociedad, la raya en mil bandas y zonas de tiempo que se mueven en todas las direcciones. (LUDMER, 2010, 18 y 19)

Para os estudos de literatura que se envolvem com uma reflexão sobre a América Latina, hoje é imperativo investigar o terreno textual, o próprio cenário linguístico no qual circulam os discursos poéticos e no qual se mesclam as línguas mestras. No caso de postularmos uma configuração de "literatura latino-americana" que inclua, na temporalidade do presente, as espacialidades/textualidades brasileiras, o entendimento cultural de América Latina se abre para as línguas de fronteira, pois o Brasil é o único país que adota o português como língua oficial. Nessa direção, as poéticas compartilhadas tornam-se um rico filão criativo esteticamente ainda pouco explorado.

Por isso, o movimento em direção a algumas vertentes poético/políticas da experimentação assim como o retorno a algumas postulações das vanguardas, neste artigo, tentam pensar a conexão entre a literatura do presente e as línguas de fronteira, lendo as derivas do portunhol/portuñol nas pegadas de uma fala nômade, configuradora e resultante da já mencionada dicção "sem-terra", que, desde a modernidade, não se deixa acomodar ao traçado dos estados oficiais ou aos mapas dos territórios e adota em seus temas a consciência crítica da arbitrariedade de algumas políticas nacionais.

Conjugada às subversões das línguas, há uma tentativa de convívio, e, nos desdobramentos de una gramática que não se deixa fixar, os sinais das práticas populares da fala, os usos linguísticos letrados e não letrados e os posicionamentos questionadores que entendem a transculturalidade como condição híbrida, acolhem e 
incluem as diferenças sem deixar de apontar traços comuns, além de suspender os tempos no marco zero das mesclas.

\section{Experimentação}

Uma vertente poética, nos primeiros anos do século XX preservou a opacidade das formas artísticas, aproximando-se da utópica ideia de criar uma língua para a América Latina, e ultrapassou todas as barreiras linguísticas e territoriais, pondo as especificidades do fazer artístico em uma zona intraduzível de experiências. Por questões teóricas, denomino esta vertente de "modernista de declino", algo que também poderia ser compreendido, fazendo uma leitura anacrônica, como pós-moderno, bem antes de que fosse inventado o termo, pois a esses trabalhos se aplica o conhecido axioma de Lyotard (1986): "todas as direções possíveis são igualmente prováveis" (p. 13). Nessa encruzilhada, situam-se os trabalhos do artista múltiplo argentino Alejandro Schultz Solari - mais conhecido como Xul Solar.

No contexto cosmopolita do Ultraismo argentino, nos primeiros anos do século $\mathrm{XX}$, emerge sua panlíngua, um idioma universal criado com bases numéricas e astrológicas com o objetivo de que todos os povos se conheçam melhor e possam se comunicar, e também o neocriollo, uma língua formada com palavras, sílabas e raízes das dominantes: o castelhano e o português. Tanto a panlíngua quanto o neocriollo são invenções poéticas de Xul Solar. Do neocriollo, criado especialmente para o Continente Americano, trago, como exemplo, um fragmento poético, publicado em 1936, na revista destiempo, editada por Jorge Luis Borges y Adolfo Bioy Casares:

\section{VISION SOBREL TRILINEO}

núo hi hial'diáfano pro empiéöme. el signo, grande ante mí, está claro en xeól umbro; escali trépölo, entón encima fórmesele otro signo igual ke tamién trepö, i hidem idem, i así muitas vezes asta ke cánsömene, ya mui alti.

déitöme nel último trilíneo 'mo en tapíz, i flotö con él. otro tal trilíneo acérkeseme y obsúbölo, i lueg’outro idem idem, etcé., nel mismo umbro núbido gris i brun.

(...)

cho' entón upasóltöme del ástrito i sou sólo unu nugro fus"puntu, i subö pa otro noche solo do no sentö ni caló nada: es mi propio peki nugri ke impídeme crusti.

mui viol'puqö i alfín ne resálgöme, ya sin ningún taro ni lembre ni gan', i sou pur'blis, pues no tenö forma ni limites; ra' periexpándöme nel cosminoche infinito do too es es puedi, hi too yi chi' pérdese, i nostro mundo es fen' despuma i mi exvida sólo una bólhita pre crepi, mui yus'.

pero esa tum bolha mui atráigeme desdese mundo, i zás yi fulmicáigöme, ra' ensártinmen los varios mis cuerpos asta kes yus' este mundo, re.

XUL SOLAR

(41,5378) 
(ésto está en criol, o neocriollo, futur lenguo del Contenente)

Aplicando variações linguísticas do espanhol ao português, passando pelo uso de prefixos gregos, latinos e com algo do guarani, os textos em neocriollo assinalam um espaço sem fronteiras, traçando uma direção contrária das escrituras regionais, que enfatizavam justamente, na língua, a cor e os marcos específicos, locais. As primeiras investigações em neocriollo remontam a 1925 e constituem una resposta ao esgotamento das formas expressivas. Xul Solar propõe um sistema colaborador e alternativo entre os idiomas, no qual - ainda que apenas nos planos estéticos - o guarani se destaca. Obviamente, embora utilizasse o neocriollo na fala cotidiana, o objetivo de Xul era menos utilitário e mais artístico e seus textos nessa língua utópica e futura permanecem no campo do imaginário.

Dando um salto no tempo e cruzando as fronteiras, a novela Mar Paraguayo, do escritor paranaense Wilson Bueno, de 1992, também institui um tipo narrativo translinguístico, produzindo os efeitos de curiosidade e de atração. A língua parece emanar de uma fonte secreta, mesmo quando explicitada em um texto "elucidário", que encerra a novela, um glossário situado ao mesmo tempo dentro e fora dela. Na trama de línguas, figuram as correspondências e os desacertos entre os vocábulos em português e espanhol - que elaboram o portunhol/portuñol — e se apresenta a dicção outra, o guarani, que une as partes, costurando tudo.

Para o poeta e teórico Néstor Perlongher, na introdução do texto,

\begin{abstract}
Wilson Bueno tiene algo de Manuel Puig (porque su escritura se basaba en la conversación...) y también algo de cronista, porque recoge un modo de hablar bastante difundido: prácticamente todos los hispanoamericanos residentes en el Brasil usan los inconstantes, precarios, volubles encuentros en la mezcla de lenguas para expresarse. Esa mezcla tan imbricada no se estructura como un código predeterminado de significación; casi diríamos que ella no mantiene fidelidad excepto a su propio capricho, desvío o error (PERLONGHER, 1992, p. 7)
\end{abstract}

A criação pelo capricho, desvio ou erro tem ecos antigos e confunde as línguas em una estética de contrabandista, que se elabora na fronteira ${ }^{3}$ e se torna produtiva pelas habilidades de semear a confusão e minar a ordem estabelecida pelas gramáticas e

\footnotetext{
${ }^{3}$ Com sentidos distintos, mas por afinidades óbvias, a temática da fronteira é recorrente em trabalhos de Literatura Comparada. Ver, por exemplo, os artigos "Fronteiras do conesul: os limites do literário" e "Imaginários do contrabando nas literaturas de fronteira" (MOVIMENTO, 2005), de Léa Masina, e também a discussão a respeito do fronteiriço que incorpora o gesto crítico e a noção de interdisciplinaridade, no livro O próprio e o alheio. Ensaios de literatura comparada (UNISINOS, 2003), de Tânia Franco Carvalhal.
} 
dicionários: “¿vale decir, por ejemplo, que en español sin, al contrario de 'sim/sí', quiere decir 'sem' - con el cual se retira a la afirmación su existencia?", pergunta Perlongher. (1992, p. 10). Mais adiante, as reflexões derridianas sobre a tradução, por exemplo, em Torres de Babel (2002), remontam ao mito bíblico da criação do mundo.

Perlongher, em movimento de identificação e retorno até o surrealismo correntino de Francisco Mandariaga, define a língua inventada por Bueno como un portunhol "gaucho-beduino-afro-hispano-guaraní”, ou "brás-hispano-guaraní." ou "hispano-guarani aportuguesado”, ou, ainda, "espaguês misionero" e pergunta: “¿Cual es (si es que hay una) la lengua de base? e: ¿a partir de cual lengua se debe empezar a leer la novela?" (1992, p. 10).

Enquanto no espaço narrativo de Mar Paraguayo se desenvolve um ato extremo de emasculação pelo corte, na linguagem, o que se intenta é levar ao suicídio por implosão as línguas-mães bem estabelecidas. Nessa direção, o guarani, trazido do fundo dos tempos, contribui para minar, por dentro, as certezas linguísticas. Na tessitura de Bueno, em comparação com os sons silenciosos das formigas, a entre-língua que ele elabora faz um trabalho subterrâneo assim como os outros animaizinhos que, ou são noturnos ou vivem ocultos, e se espalham nas entrelinhas: aranhas, cobras, escorpiões, moscas, mariposas, morcegos e vermes. Esta fauna, assim como as sobras mínimas da língua, são responsáveis pelo lirismo exacerbado, com ecos míticos, que explode em passagens mais dramáticas, quando o personagem desenvolve seus questionamentos desesperados, na vertigem do corpo e da linguagem, em um zoológico de significantes e em conjunção hermafrodita.

Produzindo efeitos sutis, a escritura demanda outros sentidos ou dizeres, a respeito dos lugares de sujeito, que perturbam a ordem do simbólico e estabelecem um espaço de tensão no jogo criador. Segundo o crítico Adrián Cangi, em addenda à edição argentina de Mar Paraguayo, de 2005, a obra é uma das pontas de uma série possível de rastrear: desde o dialeto italiano-paulista de Juó Bananére até a poética de Perlongher; desde as Galáxias, de Haroldo de Campos, e do Catatau, de Paulo Leminski, até o Mar Paraguayo, de Wilson Bueno:

De Juó Bananére a Wilson Bueno, del "dialeto macarrônico" de los años '20 al "portuñol atravesado de guaraní" de los años '90, recorremos la historia de una mutación de la lengua desde el interior del Estado expansivo que recibe las migraciones de masa a las más complejas y extrañas zonas de frontera. (...) Estos desplazamientos biográficos, los avatares de la memoria y la vertiginosa huida de la lengua materna, se inscribe en la literatura como salud, porque consisten como proponía Deleuze: en 
inventar un pueblo que falta. Juó Bananére, Wilson Bueno, Paulo Leminski, Haroldo de Campos y el propio Perlongher hicieron de sus fábulas poéticas, de sus voluntades de ficción, de sus crónicas, una zona de encuentros, donde las marcas de la biografía y la migración atraviesan la geometría de las lenguas nacionales, con la pasión de un trabajo minucioso, que inventa pueblos, especies, cuerpos y galaxias que faltaban (CANGI, 2005, p. 267-268).

A produção desta linhagem poética põe em circulação um avatar do monstruoso e aponta, na novela, as marcas de fim das narrativas do Estado moderno, já que nela flutua, também, uma paródia sociopolítica às tentativas nacionais de definição de uma língua única, que funcione como sinônimo de identidade. Algo politicamente assemelhado já foi exibido no primeiro modernismo brasileiro, nos postulados da antropofagia de Oswald de Andrade e também na poética de Mario de Andrade em Macunaíma.

A desmontagem sintática das línguas oficiais - o português e o espanhol além da contaminação generalizada e perturbadora da performance do portunhol/portuñol, através do perspectivismo e das imagens de fundo guarani, trazem ao texto instabilidade e improvisação, algo de uma força recalcada que ainda pulsa.

Diz a ambígua e fronteiriça personagem de Bueno:

Olvido guaranis y castejanos, marafos afros duros brasileños porque sei que escribo y esto es como grafar impresso todo el contorno de uno cuerpo vivo em el muro de la calle central (Bueno, 1982, p. 26-27).

\section{Portunhol/portuñol}

O escritor e editor Douglas Diegues foi quem, pela primeira vez, na década final do século XX, utilizou a expressão "portunhol selvagem" ou "portuñol salbaje" para denominar sua língua poética, utilizando-a como base para publicar seus poemas. Diegues é brasileiro, viveu muitos anos em Ponta Porã (MS), Brasil, próximo da fronteira com o Paraguai, e hoje vive em Campo Grande. Quase sempre, suas publicações frequentam suportes alternativos, os blogs e as Editoras Cartoneras ${ }^{4}$, que pertencem a uma espécie de movimento cultural iniciado na Argentina e se estende

\footnotetext{
${ }^{4}$ Entre as muitas Editoras Cartoneras da América Latina, a argentina Eloísa Cartonera é a mais antiga. Nasceu em 2003, como cooperativa criada por autores argentinos e formada por dez sócios. Desde essa época, produz livros artesanais com capas de cartão, papel recolhido nas ruas. A parte do texto, o miolo, é feita por impressão caseira, na sede da editora, nos subúrbios de Buenos Aires. Para outras informações a respeito das Cartoneras, ou para conhecer o trabalho e seus títulos, ver textos de Andréa Terra Lima citados nas Referências, ou buscar na Internet, pois todas têm seu sítio de divulgação e de vendas.
} 
atualmente ao Brasil, ao Japão e a alguns países europeus. No caso de Diegues, suas primeiras reflexões dizem respeito à visibilidade/invisibilidade do Paraguai e funcionam como metáfora ou condensação de uma América Latina em pé de guerra:

\section{CONBERSA COM CARLOS DRUMMOND DE ANDRADE EN LA NOCHE SELVAGEM TRIPLEFRONTEIRA}

Precisamos descobrir el Paraguay

escondido entre la Argentina maradonizada y el Brasil fifi

El Paraguay esse país sonâmbulo que duerme prendido

Precisamos inbentar el Paraguay!

Los kurepas son italianos que hablan español?

Los brasileiros son yankees que hablan português?

Hasta cuando vamos a querer ser franxutes fakes, alemanes truchos, judíos lambareños, italianos fraudes?

El cielo es hermoso pero nadie quiere ir al cielo,

Igual non pega subestimar las africanas...

Es necessario inbentar Paraguay y el resto del mundo

Estudiar cortezia com los greco-guarangos de la universidad de la calle

Dejar de imitar refinadas literaturas y ensinar las elites

intelectuales y los professores a bailar cumbia y cachaca pirú

Cada paraguayo tendrá su depa

su fogón su termo su aire su ducha su calefactor

salón para encuentros literários ou cafés filosoficos

y para bailar hasta el amanecer salvajes ritmos tecnos

Necessitamos elogiar el Paraguay

Es mucho más que um hermoso paraíso decadente

y muito más había sido que um país bilingüe

y muito mais dibertido que um país de mierda

com abundantes rios y su Sanber y su Areguá

y sus Rocíos y su kunu’u puréte.

Necesito adorar mais o Paraguay!

Mismo que sea impossibelle viver mais de 120 años

con un corazón de mono

y compreender del todo el portunhol selvagem de la vida y de la muerte

Necesito, necesitamos, talvez, non dar tanta bola al Paraguay

esse país tan latinoamericano, tan guaú que guarani, tan london karapé

porque ele ya se ha olvidado de nostro kunu'u puréte y de nostro beso selvagem.

El Paraguay no quiere a nadie! El Paraguay está harto de todos!

El Paraguay es otro planeta, el Paraguay nunca ha existido. Nim los paraguaios sabem

bién quem son nim de donde vienen y qué hacen aqui y mucho menos hacía dónde van.

(Diegues, Blog Portunhol Selvagem, 2001).

A memória da Grande Guerra - tríplice aliança na tríplice fronteira - é ativada nesses textos, sendo por intervenção no poético que se inventa uma língua contra o genocídio, capaz de assegurar a sobrevivência dos códigos orais, não apenas por incorporação — seguindo os desejos dos porta-vozes das modernas correntes 
oficiais —, mas pela garantia de um espaço de exposição das diferenças não assimiladas nem assimiláveis. A Guerra contra o Paraguai é o fato comum ou o "fantasma" de um passado que, para essas produções, se estipulou como "o real": lugar para onde convergem e com o qual conversam os versos produzidos no presente.

Em livros posteriores, como, por exemplo, Triplefrontera Dreams (2010), a pesquisa se amplia em torno da errâncias e das indeterminações do mapa global, como por exemplo no trecho a seguir, do poema "amantes perfectos":

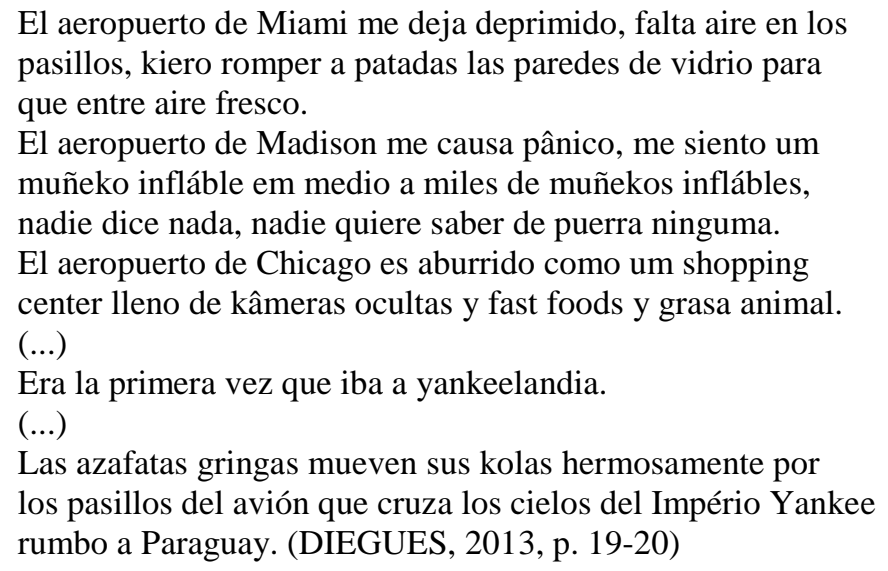

O eu poético, narrador cosmopolita, descreve suas sensações em um voo de retorno, da América do Norte à América do Sul, mesclando especificidades locais e globais em ironias típicas de um sul-americano perturbado com diferentes formações culturais e, principalmente, com o comportamento nitidamente xenófobo dos que ele denomina "yankees" ou "gringos". Nos últimos versos, a míni epopeia de retorno se encerra em comparações de cervejas, com pontos positivos para o Sul: "... ou una pilsen ño-ño,/ que era la mejor y la más barata en toda la mesopotâmia / triplefronter. (Idem, p. 26). Não por acaso, no avião e no poema, o Paraguai e a Mesopotâmia se confundem.

O poema dialoga com as expedições colonizadoras e incorpora viagens literárias, em especial a de "La prose du Transsibérien et de la petite Jeanne de France", que Blaise Cendrars escreveu no ano vanguardista de 1913, tendo como cenário um trajeto de trem, no qual se exibem velocidade, focos múltiplos e violências de contatos. Em perspectiva semelhante, o longo texto do poeta latino-americano explora a transtemporalidade como um catalisador discursivo, amarrando e encadeando cenas e espaços variáveis enquanto ruma ao seu país.

A leitura dessa "tradição do moderno" surge também nas "traduções selvagens" experimentadas por Diegues, que transpõe ao portuñol/portunhol em textos literários 
conhecidos, de várias procedências e períodos. Em Tudo lo que você non sabe es mucho más que todo lo que você sabe (2015) o famoso soneto de Baudelaire, "A uma passante", é "transbaudelairezado al portunhol selvagem" (p. 13) e outro poema, não menos famoso, "Poema em linha reta", do heterônimo pessoano Álvaro de Campos, é intitulado "Poema em línea re(c)ta", torna-se uma "Bersión transfernandopessoainventada al portunhol" (p. 16-17). Em ambos, no pé da página, acompanha um "Glossarioncito selvagem", com os termos desconhecidos espanholguarani, uma prática também realizada por Wilson Bueno, ao expor um "elucidário" no final de seus livros.

Outros escritores que de alguma forma se envolvem com o "portunhol selvagem" são Joca Reiners Terrón, do Mato Grosso, que tanto escreve em portuñol quanto em português, e Xico Sá, jornalista nascido no Ceará. Ambos vivem hoje em São Paulo. Terrón publicou, em 2008, pela Cartonera Yiyi Jambo, uma coletânea de poemas traduzidos, intitulada Transportuñol borracho, exibindo em sua página de abertura a seguinte declaração:

\footnotetext{
Lo mío es lo contrabando, lo lirikotráfico; como saber adonde se ubica la frontera si non sei onde empieza el dia y si acaba el sueño?; como conocer onde empieza el português y termina el castellano, si lo unico que sei és que el portuñol és infinito, assim como la borrachera? Lo mío es la poesia y el infinito, esa broma que llamamos vida. (TERRÓN, 2008, p. 6).
}

À estética de subversão das aduanas se soma, em Terrón, o critério da borrachera, que é o ponto de referência e a condição de montagem de suas curiosas traduções, e incluem as não menos curiosas sínteses biográficas dos múltiplos autores selecionados em sua biblioteca.

Cito algumas:

\section{IKKYÛ SOJUN}

[ El poeta nipozen más loko di todos, también conocido como EL NUBE LOKA (1394-1481); era un monje borracho; le gustavan mucho los tatúrohos y las andoriñas.]

\section{HANS MAGNUS ENZENBERGER}

[ El más grande y mayor poeta germano bibo. Grán ensaysta y bebúm di izquierda, bibe aún (1929 - ) en Munique y en mío corazón.]

\section{MALCOLM LOWRY}


[ El más grande de los borrachos; un de los escritores más marginalizados de la literatura anglo, la literatura ke nunca és marginalizada; ex-marinero, ex-cónsul y ex-todo; bibeu, bebeu, murrió (1990-1957)](TERRÓN, 2008, p. 7, 10 y 16)

O "portunhol selvagem" e as "traduções selvagens", de Diegues, e o "transportuñol borracho", de Terrón, seguem, a distância, os passos da poesia moderna, em suas relações com o humor, ainda que desdobrem o fazer escritural e frequentem uma cena transnacional, transcultural, transtemporal e midiática próxima do que Ludmer descreve como "nueva experiencia histórica" e "tiempo cero" global.

Em direção complementar, mas com algumas diferenças, Xico Sá estabelece uma relação com a prosa nos textos La mujer es un globo da muerte (2007), uma novelinha em 14 capítulos bem curtos, com subtítulo "una nuebeullita sangrenta de amor a quemmarropa", e Tripa de Cadela \& Outras Fábulas Bêbadas (2008), espécies de contos para letras de Chico Buarque, que também podem ser lidas como "Das anotações em um guardanapo no almoço solitário do dia dos pais". Desta última, destaca-se nem tanto o portunhol, mas uma dicção "cabrobol", conforme declara em entrevista a Susana Ferreira, para o Blog Portunhol Selvagem:

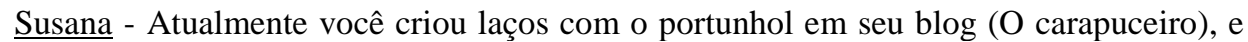
além do novo livro, não economiza em termos da língua diversa. Essa forma de linguagem usada é importante para quem fica entre os dois lados, ou é uma forma de satirizar? Xico - O portunhol selvagem, não simplesmente o portunhol, é uma nova lingua, iniciada com o amigo Douglas Diegues, escritor da fronteira do Brasil/Paraguay/Argentina, que veio para ficar. Já é um movimento grande de escribas dos três países e agora em dezembro terá o seu primeiro encontro internacional em Asunción. Cada um tem o seu portunhol selvagem, o Douglas mesmo mistura portunhol com Guarany, eu tenho um acento mais pro faroeste e pro cabrobol, que é a linguagem dos maconheiros da beira do rio São Francisco. É o novo esperanto, é a língua dos novos tempos, e uma forma de matar a solidão do português em latino-américa. (SÁ, $2008, \mathrm{~s} / \mathrm{p})$.

Assim, tanto nas vozes populares, captadas em voo e registradas em textos e em poemas, quanto nas utopias dos poetas e escritores brasileiros-latino-americanos, em torno da globalização, da crise, pessoal e nacional, do fim do século $\mathrm{XX}$ e das retomadas do pensamento teórico no que se refere às identidades e ao território, se garante uma esfera material de opacidade e de silêncio, um espaço destinado à fuga do dizer e de tudo o que é dito, uma poética que, paradoxalmente, é heterotópica: campo aberto a outras leituras.

Nas palavras de Diegues, em entrevista a Julio Daio Borges, para o Blog Digestivo Cultural, o portunhol é de propriedade coletiva: 
Qualquer um puede inventar suo portunholito selvagem onde quer que esteja. Obviamente cada lugar tem suas misérias y esplendores, suos infernos y paradaizes artificiales, suas kumbias flor de piedra y suas aburridas kachakas dolor de kuerno. Puede que lugares tengan influênzia em palabras. Pero la poesia non se faz com estar ou non em um determinado lugar, non-lugar, entre-lugar, post-lugar... La poesia se faz com palabras. Y com palabras se puede fazer poesia em qualquer parte. Estar em Nueba York ou Ponta Porã ou em la Isla de la fantasia terá alguma influenzia. Pero non es garantia de puerra ninguma. Porque hay algo que está antes de las palabras, que es la energia que cada um pone en la palabra. Manoel de Barros por ejemplo pone sua energia, sua vida, suo amor amor. Ele expressa a sua liberdade de linguagem, non al "verso ideal", a la "frase perfeita" etc e tal. Lo que se pone antes de las palabras, la energia, el esperma, el amor amor, la buesta de elefante, non importa el nombre, ere eré'a, es lo que faz la diferenza (DIEGUES, 2009, s/p).

Ainda que Xico Sá, por exemplo, declare ser as entre-línguas espécies de "esperanto", vale lembrar, por outro lado, o critério da borrachera adotado por Terrón, que põe todos os discursos sob suspeita e vem, ironicamente, dar a ver uma fala que se projeta no vazio, uma palavra ébria e nonsense. É possível que essas composições apontem para a nostalgia do encontro, a um tipo de prática literária inalcançável, se não romântica e idealizada, mas que também sobrevive meio deslocada na cena contemporânea. Assim, anacrônicas e existentes, politizadas e globalizadas, estão condenadas, desde os lugares de origem, a não permitir que nos livremos delas.

\section{Adendo}

Não teria espaço, aqui, para comentar nem os poemas em guarani, recolhidos e reescritos (ou traduzidos) pela poeta e tradutora Josely Vianna Baptista, nem as produções português-espanholadas, ou vice-versa, de Aldir Garcia Schlee, na fronteira sul do Brasil com o Uruguai. Como estratégia, vale assinalar novamente o liricotráfico e a possibilidade de transportar e incluir esses feitos e escritos em cartografias afetivas.

Em pulo ao passado, resgatei na epígrafe o trecho de um poema de Ascenso Ferreira (1939), do ponto de vista dos veteranos, e resgato também, para encerrar, um samba guerreiro, recolhido por Cerqueira (1980), composição coletiva dos combatentes brasileiros na Guerra do Paraguai:

\footnotetext{
A polícia não quer que eu sambe aquí. Aquí mesmo hei de sambá!

A polícia não quer que eu sambe aquí.
} 
Esses sambas, resultantes da presença em massa dos negros na guerra, tanto integrando as tropas regulares dos Voluntários da Pátria - em nome de uma suposta libertação da condição de escravo, no caso de sobrevivência —, quanto naquelas de recolha não tão voluntária —, a fim de substituírem os senhores, no sistema dois escravos por um branco - nos remete a uma faceta ainda mais violenta e pouco exposta quando se trata da guerra contra os paraguaios: entre outros tantos interesses, há um acordo tácito dos exércitos e dos governantes de colocarem negros e índios a enfrentarem-se no campo de batalha, como implementação de uma política étnica em nome de um branqueamento colonizador.

Assim, a poética do portunhol, na qual, em tempo presente, Diegues identifica uma amplitude transnacional e translinguística, vai na contramão do(s) genocídio(s), assegurando a sobrevivência das línguas e a memória do conflito nos termos oscilantes e provisórios dos vocábulos e expressões mesclados e no esforço de enfrentamento e convivência entre os povos, desde a chegada dos invasores europeus.

Considerando que o Brasil e os demais países da América Latina ainda estão acertando contas com a sua população indígena, com os remanescentes de escravos e com os outros grupos de imigrantes legais que para aqui vieram durante o processo de colonização, percebe-se, no século XXI, que a guerra ainda está em curso e que o Paraguai continua aqui e agora. Como deriva, a literatura é contrabandeada nas fronteiras, e, como delito explícito, se configura através de dispositivos bélico-poéticos de subversão, disfarce e enfrentamento.

\section{Referências}

BITTENCOURT, Rita L. F. Guerra e poesia: Dispositivos Bélico-Poéticos do Modernismo. Porto Alegre: UFRGS, 2014.

. "O comparatismo à beira do fim: tensões do híbrido poético". In. SCHMIDT, Rita T. (Org.). Sob o signo do presente: intervenções comparatistas. Porto Alegre: ed. da UFRGS, 2010.

BUENO, Wilson. Mar paraguayo. Buenos Aires: Tsé Tsé, 2005. póstuma). Mascate. Pî̀'aitteguivé. Paraguai/Ponta Porã, MS: Yiyi Jambo, 2014 (Edição 
CELADA, Maria Tereza. "Acerca de errar por el portuñol". In. Revista Tsé-Tsé. Números 7-8. Buenos Aires: 2000.

DELEUZE, Gilles; GUATTARI, Félix. Kafka. Por uma Literatura menor. Trad. Júlio C. Guimarães. Rio de Janeiro: Imago, 1977.

DERRIDA, Jacques. Torres de Babel. Trad. Junia Barreto. Belo Horizonte: UFMG, 2002.

DIEGUES, Douglas. "Conbersa com Carlos Drummond de Andrade en la noche selvagem triplefrontera". Blog Portunhol Selvagem. Disponível em: <http://portunholselvagem.blogspot.com.br/>. Acesso em 18 mar 2013.

Triple Frontera Dreams. Paraguai/Ponta Porã, MS: Yiyi Jambo, 2010.

. Tudo lo que você non sabe es mucho más que todo lo que você sabe. Santa Maria, RS: Vento Norte Cartonero, 2015.

Entrevista: Douglas Diegues. Disponível em: $\langle$ http://www.digestivocultural.com/entrevistas/entrevista.asp?codigo=28\&titulo=Dougl as_Diegues $>$. Acesso em out 2016.

LIMA, Andréa Terra. A estética do (in)desejável: uma margem catadora. Monografia de Conclusão de Curso de Letras: UFRGS, 2009.

Glauco Mattoso e as Editoras Cartoneras: Uma leitura. Monografia de Conclusão de Especialização em Literatura Brasileira. UFRGS, 2011.

Nos cruzamentos da selvageria: uma poética do portunhol. Dissertação de Mestrado. Curso de Letras: UFRGS, 2013.

LYOTARD, Jean-François. O Pós-moderno. Trad. Ricardo C. Barbosa. Rio de Janeiro: José Olympio, 1986.

LUDMER, Josefina. "Temporalidades del presente". In. Márgenes/Margens -revista de Cultura. Belo Horizonte, Buenos Aires, Mar del Plata, Salvador. Número 2, 2002.

Aquí América latina. Una especulación. Buenos Aires: Eterna Cadencia Editora, 2010.

LYOTARD, Jean-François. O Pós-moderno. Trad. Ricardo Corrêa Barbosa. Rio de Janeiro: José Olympio. 1986.

MOREIRAS, Alberto. A exaustão da diferença. A política dos estudos culturais latinoamericanos. Trad. Eliana Reis e Glaucia R. Gonçalves. Belo Horizonte: UFMG, 2001.

RAMA, Angel. Transculturación narrativa en América latina. Buenos Aires: El Andariego, 2007. La ciudad Letrada. Chile: Tajamar Editores Ltda., 2004.

SÁ, Xico. La mujer es um Globo da Muerte. Paraguay, Asunción:. Yi Yi Yambo, 2007. 
Tripa de Cadela \& Outras Fábulas Bêbadas (contos). São Paulo: Dulcineia Catadora, 2008.

Xico Sá desmacunaimaniza el futuro com ternura caliente! Entrevista a Suzana Ferreira. Disponível em: <http://portunholselvagem.blogspot.com.br/2008/08/xico-sdesmacunaimaniza-el-futuro-com.html>. Acesso em out 2016.

VIRNO, Paolo. Palabras con palabras. Poderes y límites del lenguage. Trad. Eduardo Sadier. Buenos Aires: Paidós, 2004.

El recuerdo del presente. Ensayo sobre el tiempo histórico. Trad. Eduardo Sadier. Buenos Aires: Paidós, 2003.

TERRÓN, Joca Reiners. Transportuñol Borracho. Paraguai/Ponta Porã, MS: Yiyi Jambo, 2008. 